\title{
Numerical analysis of the vacuum infusion process for laminated composites with different fiber orientations
}

\author{
F.J. Hurtado ${ }^{\mathrm{a}}$, A.S. Kaiser ${ }^{\mathrm{a}, *}$, A. Viedma ${ }^{\mathrm{a}}$, S. Díaz \\ ${ }^{a}$ Dpto. Ingeniería Térmica y de Fluidos, Universidad Politécnica de Cartagena, \\ Doctor Fleming s/n, 30202 Cartagena, Spain \\ ${ }^{b}$ MTorres Diseños Industriales S.A.U. Ctra. El Estrecho-Lobosillo, Km 2. 30320 - \\ Fuente Álamo, Murcia, Spain
}

\begin{abstract}
The vacuum infusion (VI) is a process usually applied to manufacture large structures of composite materials, such as wind turbine blades. Present work analyzes the macroscopic resin flow through a laminate of fiberglass plies with different orientations, during the filling stage of the VI process to manufacture two different pieces. The pressure inside the mold, velocity vectors and the resin inlet mass flow are studied through a 3D numerical modeling under non-steady conditions validated experimentally. The numerical model simulates each ply of the laminate like an individual porous media and takes into account the stacking sequence of the laminate. The influence of the permeability values of the distribution media and the fiberglass laminate on the evolution of resin infusion is analyzed. The numerical model reproduces the effects of the stacking sequence and race-tracking on the resin flow front.
\end{abstract}

Keywords:

Vacuum infusion, Liquid Composite Molding, Computational modeling.

${ }^{*}$ Corresponding author. Tel. no.: +34 968325 984. Fax no.: +34 968325 999. E-mail address: antonio.kaiser@upct.es (A.S. Kaiser)

Preprint submitted to Composites Part A: Applied Science and Manufacturing October 6, 2014 


\section{Nomenclature}

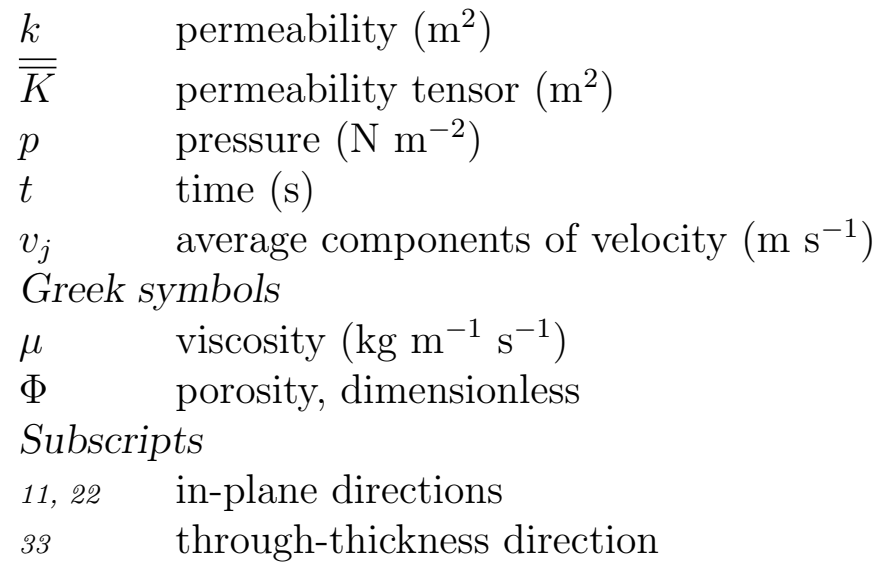

\section{Introduction}

The fiber-reinforced plastics are composite materials which combine low weight, high mechanical strength and good corrosion resistance. Nowadays, the composite materials are widely used in the aerospace industry due to its characteristics and are replacing the traditional engineering materials. Liquid composite molding (LCM) is a technology able to manufacture highly complex parts of composite materials with better control of properties, higher content of the reinforcing material, lower emissions of chemicals and lower cost than other processes. The LCM technologies involve processes to manufacture composite parts by infusion of a thermoset resin in liquid state to impregnate a fiber material which is placed in a closed mold. The composite part is integrated by the fiber reinforcing material and the resin cured. Vacuum infusion (VI), also called Vacuum Assisted Resin Infusion (VARI) or Liquid Resin Infusion (LRI), is a LCM process in which the mold cavity is sealed by a membrane or vacuum bag and resin is forced into the mold since air is removed by a vacuum pump. VI is used in the manufacture of large components, as wind turbine blades, due to the advantages over the traditional resin transfer molding, such as lower tooling cost.

The quality and properties of manufactured part is influenced by several parameters. In composites for special applications, the fiber reinforcing material is set up by a laminate of multiple layers stacked with different orientations according to a stacking sequence. The mechanical properties of the 
resulting composite in the load direction depend on the stacking sequence of the laminate (Mallick [1])). Moreover, the fatigue life of multilayered composites (Bertin et al. [5]) and the mechanical properties and failure behavior of joints in composite laminates (Park [7], Khashaba et al. [8]) are influenced by the stacking sequence. Thereby, the stacking sequence optimization is analyzed in several studies (Ghiasi et al. [10], Le-Manh and Lee [9]). Regarding to the mold filling process, the locations and shape of the inlet gates and outlet vents of the mold affect directly the pressure inside the mold, the filling time and the successful and complete impregnation of the laminate by the resin. Furthermore, entrapment of air or resin emissions causes voids at mesoscopic scale in the laminate, which degrade the mechanical properties of the resulting composite material (Holmberg and Berglund [2], Liu et al. [3], Scott et al. [4]).

The prediction of flow behavior during the filling mold stage is crucial to obtain a high quality product and develop an efficient process with adequate filling strategies to avoid dry areas and decrease the mold filling time. Since the traditional trial-error methods are costly and time consuming, numerical simulation emerges as an effective alternative to design and optimize the molding process. To carry out accurate numerical models is required knowledge of several experimental parameters such as the geometry of the mold, the resin properties and the porosity and permeability values of the fiber materials. One of the most critical factors in setting the boundary conditions of the numerical model is the knowledge of permeability values of the reinforcing material, due to it determines the resin flow behavior during the mold filling stage. Since different experimental methods have been developed for the measurement of permeability values (Liu et al. [11] or Endruweit and Ermanni [12], for instance), the standardization of procedure and deviation of measures are still under discussion (Vernet et al. [13]). The permeability is mainly dominated by the geometry of the porous media, which can vary considerably from point to point on a microscopic level. This variation can be a consequence of the manufacturing process, the handling of the material, the sample preparation or the compression rate when closing the mold. Hoes et al. [14] show that the permeability is not a material property that can be characterized by one single value, but it exhibits a statistical distribution. Due to the reinforcing material heterogeneity, the control methods of the infusion process may be focused not only in the control of the vacuum pressure or of the inlet mass flow (Modi et al. [15]) but also to act locally in case low 
permeability areas are detected (Johnson and Pitchumani [16]).

The macroscopic flow and the shape and location of gates and vents can be analyzed through numerical models, which provide a prediction of the infiltration time, the resin flow front position, the pressure distribution and the velocity vectors inside the mold during the process. Several studies carry out numerical models of the molding process. Grujicic et al. [17] analyzed the heating effects on a two-dimensional mold filling model. Dong [18] developed a method to extrapolate the results of a 2D simulation of RTM to 3D VARTM and to select the distribution media properties. Montés and Sánchez [19] introduced a computational technique for 2.5D domains to optimize shape and location of the inlet gates. A numerical model for the reactive resin flow was proposed by Tan and Pillai [20]. The deformation of the reinforcement material due to flexibility of cover in vacuum-assisted resin infusion was studied in order to predict thickness variations during the filling stage (Trochu et al. [21]) and study the post-filling behavior (Simacek et al. [22]). Several numerical methods were carried out for the estimation of permeability values in complex and three-dimensional parts (Liu and Hwang [23]). The dual scale of the reinforcement materials used in the production of composites is analyzed by Kuentzer et al. [24], through a finite element/control volume based numerical simulation (LIMS - liquid injection molding simulation). Differences in temperatures and cure distribution between macroscopic pores and tow regions were studied by Tan and Pillai [25]. The air entrapment on dual scale resin flow was analyzed by DeValve and Pitchumani [26]. Nevertheless, the simulation of the VI process require to carry out tridimensional models, due to the presence of different flow media and different orientations of each ply, and the numerical modeling of the resin flow through macroscopic pores (spaces between the fiber tows) and microscopic pores (gaps between the filaments into each fiber tow) in dual-scale porous media demands prohibitive computation times for complex or large domains.

Present work studies the flow of resin through a fiberglass laminate set up by multiple layers with different orientations during the mold filling stage of a vacuum infusion process by a 3D numerical model, in which each ply of the laminate is modeled like an individual porous media. The numerical results of flow front position on the distribution media and on the bottom ply of the laminate are compared with the data obtained by an experimental test. The velocity vectors and the pressure contours inside the mold are analyzed. The 
influence of permeability values of distribution media and of the fiberglass material on the resin distribution inside the mold is also discussed. The aim of the numerical model is to provide a robust method for the optimization and the analysis of local effects during the resin infusion process in the manufacture of complex or large three-dimensional geometries, taking into account the different orientations of the plies of the laminate. The influence of the stacking sequence, the resin infusion in laminated composites performed by fabrics with significant different permeability values or fiber volume fractions and the race-tracking effect can be also studied by the numerical model.

\section{Experimental research}

To validate the numerical model proposed, experimental resin infusion during manufacture of two pieces of laminate composite is performed. The VI experimental system is shown in Fig. 1. The preform of laminate reinforcing material is placed on a transparent rigid surface, in order to observe the infusion of resin through the bottom of the preform. A distribution media with high in-plane permeability is installed on top of the preform to accelerate the superficial resin flow. The runner is set to load the resin flow on the distribution media. The resin flow is driven from a storage tank to the runner by the inlet gate. The set is covered by a vacuum bag. The vent is installed in the contour of the lowest layer of the laminate. The resin infusion is leaded by removing the air inside the mold through a vacuum pump. The

positions of the flow fronts in the top layer (on the distribution media) and in the bottom layer (under the laminate) are measured during the experimental molding process. 


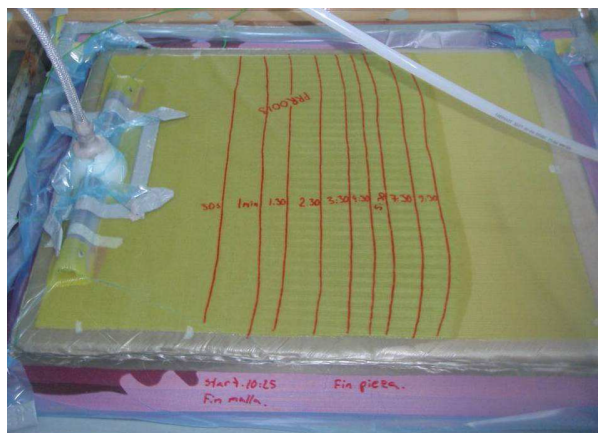

(a)

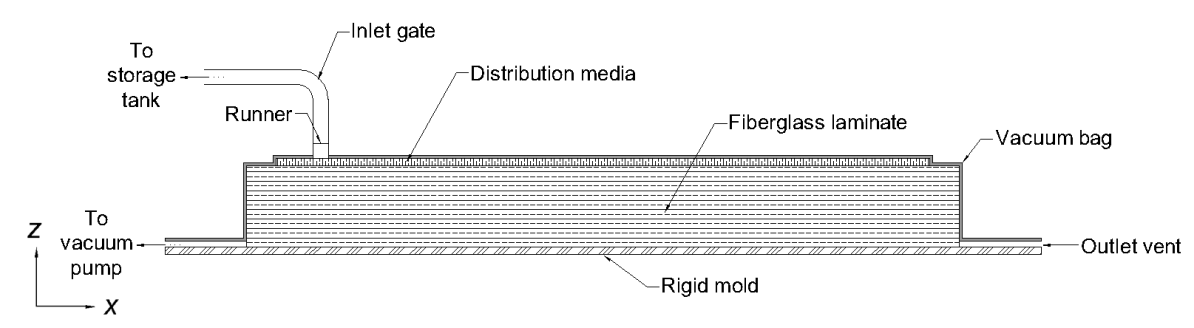

(c)

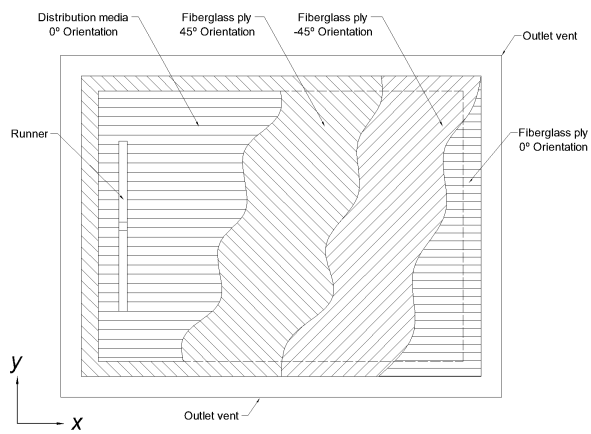

(b)

Figure 1: Vacuum infusion process a) Experimental overview (Courtesy of MTorres). b) Assembly diagram, top view with fiber orientations c) Assembly diagram, central cross section.

The two pieces of composite material manufactured through VI have identical dimensions in the in-plane directions $(800 \times 600 \mathrm{~mm})$, varying only the number of layers. The reinforcing material perform is composed by fiberglass layers $(0,75 \mathrm{~mm}$ thickness $)$, in which each ply has a certain fiber orientation to $0^{\circ}, 45^{\circ}$, or $-45^{\circ}$. The laminated composite $\mathrm{A}$ is composed of 14 layers, with a symmetric stacking sequence of $[45 /-45 / 45 /-45 / 0 / 0 / 0]_{s}$, while the laminated composite $\mathrm{B}$ is composed of 40 , with a stacking sequence of $[45 /-45 / 0 / 0 / 0 / 0 / 0 / 0 / 0 / 0 / 45 /-45 / 0 / 0 / 0 / 0 / 0 / 0 / 0 / 0 / 0 / 45 /-$ $45 / 0 / 0 / 0 / 0 / 0 / 0 / 0 / 0 / 0 / 45 /-45 / 0 / 0 / 0 / 0 / 45 /-45]$.

The experimental permeability values of the fiberglass plies and of the distribution media was obtained by a similar method to that exposed by Ferland et al. [27]. The edge of the fabrics was carefully sealed in order to avoid the inaccuracies in the permeability measure produces by the race tracking (Berg et al. [28]). One of the most critical factors in the simulation 
of resin infusion processes is the setting of the permeability value of the reinforcing material in the through thickness direction. Although different methods (Scholz et al. [6], for instance) are presented to determine it, there is a high difficulty to determine the actual value of the permeability in the through thickness direction in infusion process with flexible cover, due to its value is influenced by the fiber volume fraction, which is determined by the preform compaction. The computation of the permeability value as a function of the pressure field and of the preform compaction leads to calculate nonlinear equations in a non-steady domain and increases significantly the computation time. Due to the aim of the numerical model presented is to analyze the influences of local effects and of the stacking sequence on the resin flow in complex or large domains, the perform compaction is not considered, and the equivalent permeability of the fiberglass laminate in the through thickness direction was fitted numerically for the studied stacking sequences.

Although, the stacking sequence may significantly influence the throughthickness permeability in laminates of unidirectional fabrics (Sas et al. [29]), no significant differences were detected on the value of the permeability in the through thickness direction of the stacking sequences studied. The permeability values relative to the permeability in the through thickness direction $\left(3,5 \cdot 10^{-13} \mathrm{~m}^{2}\right)$ of the fiberglass fabric are shown in Table 1.

\begin{tabular}{lccc}
\hline Permeability & $\begin{array}{c}0^{\circ} \text { Orientation } \\
\text { principal axes }\end{array}$ & $\begin{array}{c}\text { Distribution media } \\
\text { Relative permeability }\end{array}$ & $\begin{array}{c}\text { Fiberglass fabric } \\
\text { Relative permeability }\end{array}$ \\
\hline$k_{11}$ & $y$ & 4090 & 62 \\
\hline$k_{22}$ & $x$ & 3540 & 15 \\
\hline$k_{33}$ & $z$ & 3080 & 1 \\
\hline
\end{tabular}

Table 1: Permeability tensor components. Relative values to the permeability in the through thickness direction of the fiberglass fabric

Experimental tests have been developed under isothermal conditions. The epoxy resin, which made up the matrix of pieces of composite material, has a density of $1,100 \mathrm{~kg} / \mathrm{m}^{3}$ and a viscosity of $0,25 \mathrm{~Pa} \cdot \mathrm{s}$. A slow hardener curing agent is used and the total curing time of the epoxy resin is six hours. A maximal variation of $5 \%$ on the resin properties was detected during the first hour of reaction, so that the resin curing process becomes apparent after the mold filling stage. 


\section{Governing equations}

\subsection{Inital assumptions}

As the experimental test was performed at constant temperature and the curing process of the resin starts in a significant way after the mold filling stage, the energy equation is not considered on the numerical model and the resin is assumed to be an incompressible non-reactive fluid, with constant properties during the infusion process. Assuming that the fabrics behind the resin flow front are saturated and due to the low Reynolds number, the resin flow can be modeled by the Darcy's law (Eq. (1)) for porous media (Darcy [30]).

$$
\vec{v}=-\frac{k}{\phi \cdot \mu} \cdot \nabla p
$$

Where $v$ is the resin velocity, $k$ and $\phi$ are the permeability and porosity of the preform, $\mu$ is the dynamic viscosity of the resin and $\nabla p$ is the pressure gradient across the preform. Since the aim of the proposed model is to study the local effects in the resin flow front, no relaxation of the vacuum bag and preform compaction are taken into account, in order to reduce the computational cost of the model, and a constant fiber volume fraction of $53 \%$ for the fiberglass and of $20 \%$ for the distribution media is considered. Furthermore, no effect of draping in the permeability values has been considered, as the experimental tests were flat.

When the race-tracking is studied in the numerical model, the governing equations of the resin flow within the free fluid domain (not filled with porous

media) at the edges of the laminate are the Navier-Stokes ones. According to the exposed assumptions, the interface tracking between the air and the resin is governed by a continuity equation for the volume fraction of the resin (Eq. (2)).

$$
\frac{1}{\rho}\left[\frac{\partial}{\partial t}(\nabla \rho)+\nabla(V \rho \vec{v})\right]=0
$$

A single momentum equation is solved throughout the domain, and the resulting velocity field is shared among the phases. The momentum equation (Eq. (3)) is dependent on the volume fractions of all phases through the properties density and viscosity. 


$$
\frac{\partial}{\partial t}(\rho \vec{v})+\nabla(\rho \vec{v} \vec{v})=-\nabla p+\nabla\left[\mu\left(\nabla \vec{v}+(\nabla \vec{v})^{T}\right)\right]+\rho g+\vec{F}
$$

\subsection{Fiber orientation modeling}

The resin flowing through the reinforcement material during the mold filling stage is mainly dominated by the pressure gradient inside the mold, which is determined by the geometry of the part, the locations of the gates and vents and the permeability values of the different fabrics that make up the laminate. In order to model correctly the permeability of the laminate, some considerations must be made. Each of the fiberglass plies that form the stack, taken individually, is an anisotropic porous material with the permeability tensor given by a diagonal matrix if the principal axis (eigenvectors of the linear relation between pressure gradients and flow velocity) are taken as

the reference system. This diagonal tensor $\overline{\bar{K}}$ is formed by the permeability (eigenvalues) of the layer in the three principal axis $(11,22,33)$, according to Eq. (4).

$$
\overline{\bar{K}}=\left[\begin{array}{ccc}
k_{11} & 0 & 0 \\
0 & k_{22} & 0 \\
0 & 0 & k_{33}
\end{array}\right]
$$

When plies with different orientations are stacked together and a common reference system $(x, y, z)$ must be used, the permeability tensor $\overline{\overline{K^{\prime}}}$ of a single ply is obtained by a change of basis matrix Q, as showed in Eq. (5).

$$
\vec{v}_{(11,22,33)}=-\frac{1}{\phi \cdot \mu} \cdot \overline{\bar{K}} \cdot \nabla p_{(11,22,33)} \longrightarrow \vec{v}_{(x, y, z)} \cdot Q=-\frac{1}{\phi \cdot \mu} \cdot \overline{\bar{K}} \cdot Q \cdot \nabla p_{(x, y, z)}
$$

For instance, a ply with the principal axis oriented $45^{\circ}$ to the common reference system, as depicted in Fig. 2, will have a permeability tensor given by Eq. (6). 


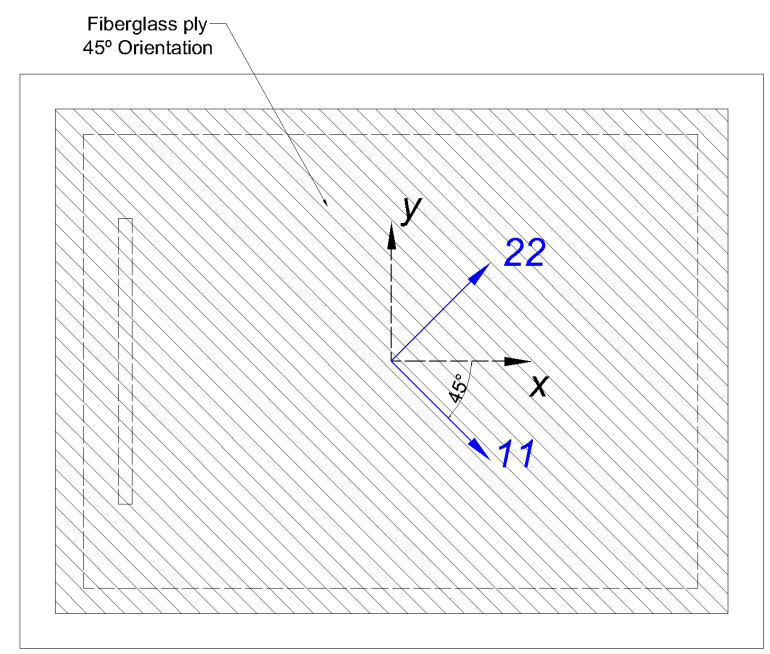

Figure 2: Main directions of permeability versus space directions at plies with $45^{\circ}$ orientation.

$$
\overline{\overline{K^{\prime}}}=Q^{-1} \cdot \overline{\bar{K}} \cdot Q=\left[\begin{array}{lll}
\frac{k_{11}+k_{22}}{2} & \frac{k_{11}-k_{22}}{2} & 0 \\
\frac{k_{11}-k_{22}}{2} & \frac{k_{11}+k_{22}}{2} & 0 \\
0 & 0 & k_{33}
\end{array}\right]
$$

For this layer, taken as an example, the flow velocity and the pressure gradient are no longer parallel vectors and the relationship between them is given by Eq. (7).

$$
\vec{v}=\left\{\begin{array}{c}
v_{x}=-\frac{1}{\phi \cdot \mu} \cdot\left(\frac{k_{11}+k_{22}}{2} \frac{\partial p}{\partial x}+\frac{k_{11}-k_{22}}{2} \frac{\partial p}{\partial y}\right) \\
v_{y}=-\frac{1}{\phi \cdot \mu} \cdot\left(\frac{k_{11}-k_{22}}{2} \frac{\partial p}{\partial x}+\frac{k_{11}+k_{22}}{2} \frac{\partial p}{\partial y}\right) \\
v_{z}=\frac{-k_{33}}{\phi \cdot \mu} \frac{\partial p}{\partial z}
\end{array}\right\}
$$

To reproduce this effect in a laminate formed by plies of different orientations stacked together, the discretization used in the numerical model must conserve the same structure and the cells must defined in layers matching the actual plies, with the aim to define different porous media for each ply of the laminate. In this way, the permeability tensor used in each porous media will be defined according to the process presented to plies with $45^{\circ}$ 
orientation, and the actual effect of the pressure gradient on the flow velocity vector will be reproduced in each point.

\section{Numerical modeling}

\subsection{Computational domain}

A numerical model is carried out for each of the manufactured pieces, laminated composite $\mathrm{A}$ and $\mathrm{B}$, which differ only by the number of plies of the laminate. The computational domain of the numerical model is shown in Fig. 3. The domain reproduces the different components of the experimental setup, the resin inlet gate, the runner, the distribution media, each ply of the fiberglass preform by different porous media, and the vacuum vent.

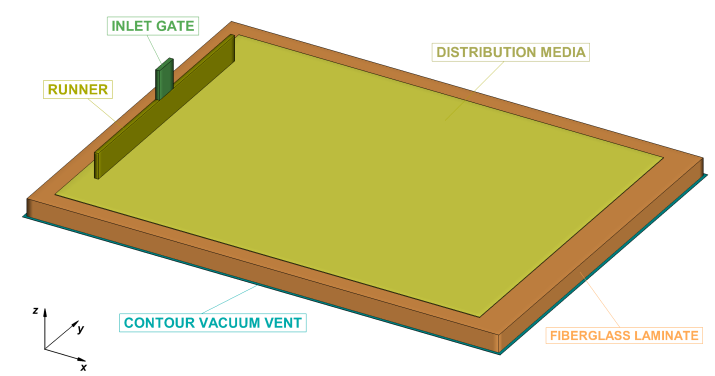

Figure 3: Computational domain and boundary conditions for the VI process.

\subsection{Boundary conditions}

The next boundary conditions are defined in the regions depicted on Fig. 3:

- Entry/exit sections. The continuity condition is imposed in the inlet section and outlet vent and the streamwise variations of velocity components are neglected. Experimental boundary conditions for relative pressure are used, corresponding to $-10.971 \mathrm{~Pa}$ at the inlet section (due to change in height between the storage tank and the inlet section) and $-101.325 \mathrm{~Pa}$ in the outlet section.

- Porous media. The distribution media and each ply of the laminate is modeled as an independent porous media according to the Darcy's law, defined by the porosity and permeability experimental values and the principal 
axes of permeability depending on the orientation of each ply. With the aim to reduce the computational time cost of the numerical model and to avoid the simulation of the free surface along the inlet gate and the runner, these channels are simplified by porous media with an equivalent permeability to reproduce the pressure drop to that calculated from Poiseuille's law, since the flow through these channels can be considered laminar during the infusion process. The results of modeling the flow in these channels like a free fluid flow or like a flow through an equivalent porous media were compared; no significant influence on the infusion process was noted.

- Walls. The no-slip boundary condition is imposed in the rigid mold and the vacuum bag. Due to the inlet gate and the runner are simplified as equivalent porous media, shear stress is considered equal to zero in the walls of these channels.

- Initial conditions. To initialize the transient calculation, the channels and the porous media inside the mold cavity are considered under vacuum at the recorded conditions in the experimental test.

\subsection{Numerical approach}

The governing equations are discretized and solved numerically in the domain showed on Fig. 3 by using the general-purpose code Fluent v.6.3.26 (FLUENT [31]) based on a finite volume procedure. The equations are discretized using the PRESTO scheme, which is similar to the well-known staggered-grid scheme. To avoid the appearance of false diffusion, the results are achieved employing the linear third-order 'quick' scheme (Leonard [32]). The SIMPLE algorithm is used to solve the coupling between continuity and momentum equations through pressure.

Air and resin are considered as two immiscible fluids and the movingboundary problem is solved under non steady conditions by a single set of momentum equations, tracking the volume fraction of each of the fluids throughout the domain by the volume of fluid model.

With regard to numerical convergence, for each time step, the criterion was $\left|\left(\xi^{i+1}-\xi^{i}\right) / \xi^{i}\right| \leq 10^{-5}$, where $\xi$ can stand for any of the dependent variables and $i$ denotes the iteration number; besides the normalized residuals

for mass and momentum variables for the full flow field had to be below $10^{-5}$. 
The time step of the transient computation was chosen by one side to satisfy the Courant limit and on the other to get sufficiently accurate solutions.

Structured, non-uniform meshes are employed to obtain the numerical results. The accuracy of the numerical results was tested by a grid dependence study. For the numerical model of the laminated composite A, several meshes were studied, up to 889.896 elements. The selected mesh corresponds to a relationship of compromise between the number of elements and the accuracy in the simulation of the resin flow front. The presented results are obtained by using a structured tetrahedral mesh integrated by 81.376 elements for the model of the laminated composite A, and by 206.176 for the model of the laminated composite B.

\section{Results and discussion}

\subsection{Validation of the model}

The transient simulation results provide the evolution of resin flow during the mold filling stage. The tracking of the flow front positions during the infusion process obtained by the numerical model of laminated composite A is shown in Fig. 4.

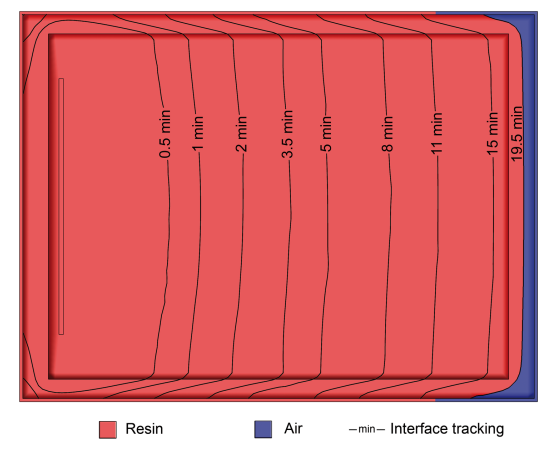

Figure 4: Numerical results of the in-plane evolution of the flow front on the distribution media during the molding process of the laminated composite A.

With regard to the transient simulation for the laminated composite A, it can be observed in Fig. 5 that the numerical results obtained for flow front position, depending on process time, follow a same trends that the experimental results, with an average deviation of $4 \%$ to the flow front position on 
the distribution media and $5 \%$ to the flow front position on the bottom ply of the laminate.

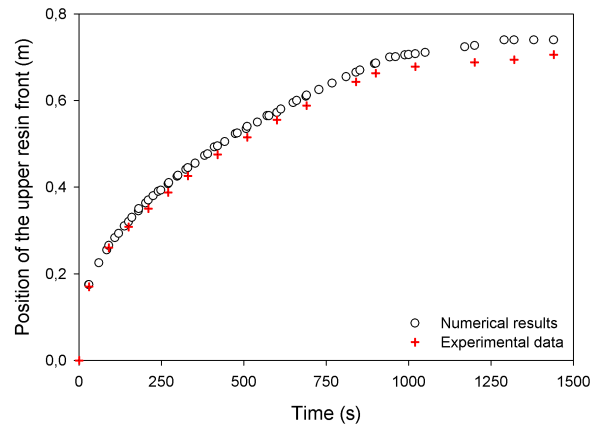

(a)

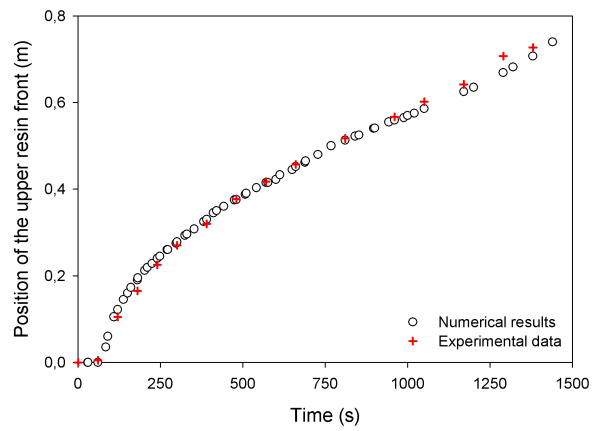

(b)

Figure 5: Experimental data and numerical result of laminated composite A a) Flow front position on the distribution media. b) Flow front position on the bottom ply of the laminate.

The evolution of the upper and bottom flow front positions obtained by the numerical model for the laminated composite B are shown in Fig. 6. The average deviations are respectively equal to $2 \%$ and $5 \%$, compared with the experimental measure.

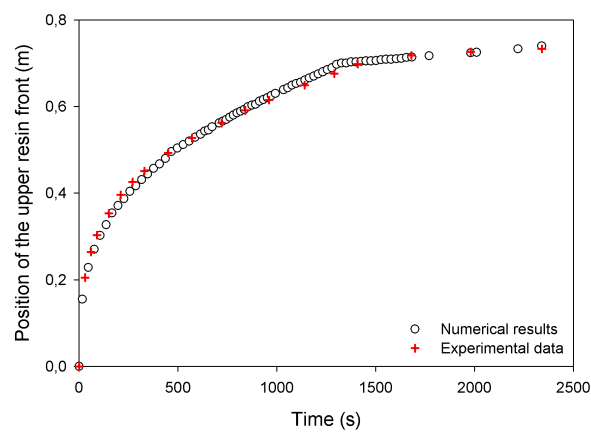

(a)

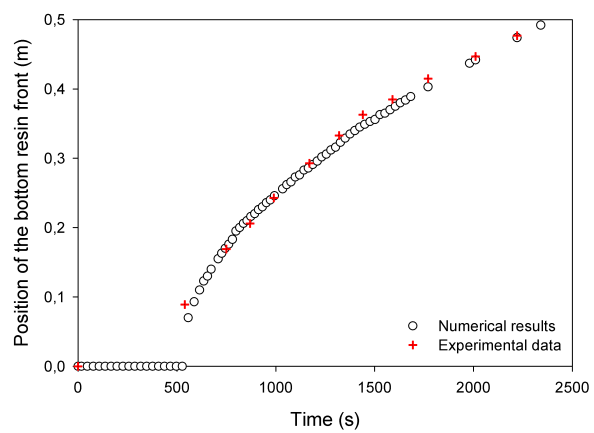

(b)

Figure 6: Experimental data and numerical result of laminated composite B a) Flow front position on the distribution media. b) Flow front position on the bottom ply of the laminate. 
The numerical model reproduces accurately the velocity vectors in each ply of the laminate, considering the different orientations, as shown in Fig. 7. Air velocity ahead the resin front increases in plies with orientation of $45^{\circ}$ and $-45^{\circ}$, due to the convergence of the streamlines in the direction of highest permeability. The lower velocity in plies oriented at 0 degrees is due to in these plies the velocity components keep up the pressure gradient direction and the streamlines tend to head for the vacuum vent.

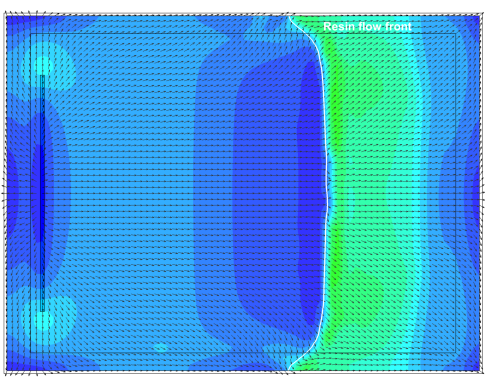

(a)
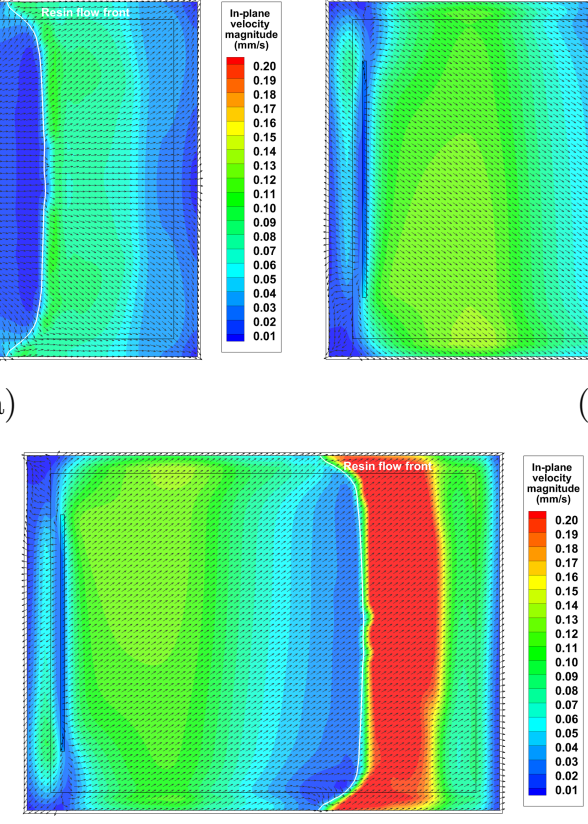

(c)

Figure 7: In-plane velocity vectors and contours at a certain time of the molding process on tree different plies with different orientations of composite A. a) $0^{\circ}$ orientation. b) $45^{\circ}$ orientation. c) $-45^{\circ}$ orientation.

The 3D multiphasic transient model reproduces the resin flow front during the mold filling stage of the VI process for laminated composites, in which the curing process may be negligible during the mold filling stage, with a low deviation. 


\subsection{Qualitative description of the flow}

The infiltration time, the resin flow front position (Figs. $4-6$ ), the velocity vectors (Fig. 7) and the pressure distribution in each ply of the laminate can be studied through the analysis of the numerical results. During infusion process, the pressure contours inside the mold evolve as a function of the resin front position, as shown in Fig. 8. At any time of the process, pressure contours are linked to the position of the interface between air and resin, due to the large difference between the properties of both fluids.

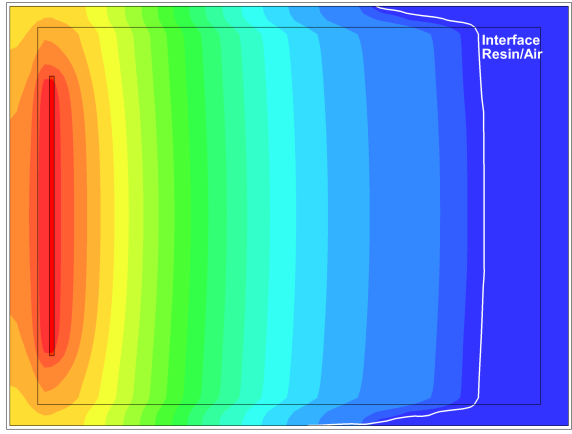

(a)

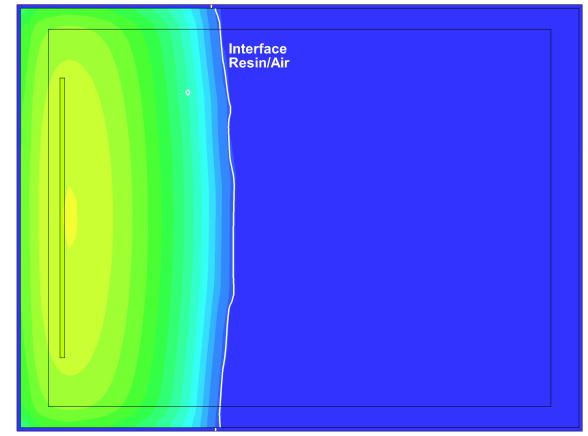

(b)

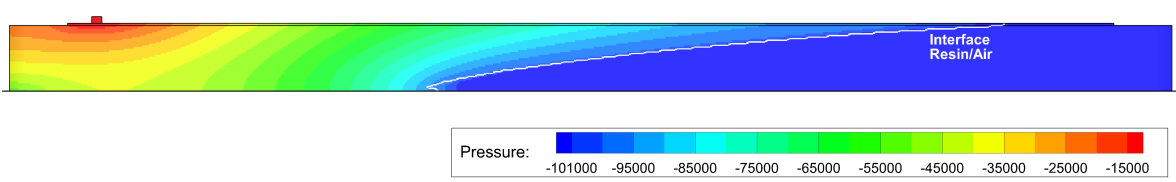

(c)

Figure 8: Pressure contours at a certain time of the molding process a) In-plane pressure contours in the distribution media. b) In-plane pressure contours in the lower ply of the laminate. c) Pressure contours in the central cross section of the laminate.

During the molding process, the mass flow of resin at the inlet section decreases sharply with increasing the volume of resin inside the mold, due to the evolution of pressure contours inside the mold according to the resin infusion progression. Inlet mass flow of resin in function of the wet volume fraction of the laminate is show in Fig. 9. Four different tendencies or stages can be observed in the evolution of the inlet mass flow. The four stages can be differentiated by three events during the mold filling process: the filling 
of the runner, the reaching of the bottom ply of the laminate by resin, and the filling of the distribution media.

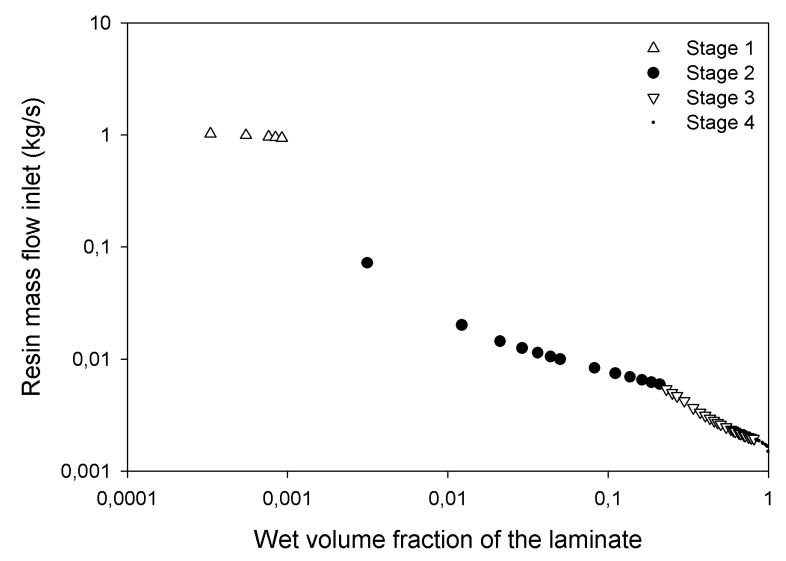

Figure 9: Inlet mass flow of resin versus the wet laminate volume fraction.

\subsection{Influence of the permeability values}

With the aim to study the influence of permeability values on the resin flow fronts and mold-filling time, seven different cases were solved. In each case, only one of the permeability values is reduced in five times from its experimental value according to Table 2 . The evolution of resin flow fronts of the cases studied with different fiberglass permeability values is shown in Fig. 10, and with different permeability values of the distribution media is shown in Fig.Fig. 11. 


\begin{tabular}{ccccccc}
\hline \multirow{2}{*}{ Case } & \multicolumn{2}{c}{ Fiberglass fabric } & \multicolumn{3}{c}{ Distribution media } \\
& $k_{11}$ & $k_{22}$ & $k_{33}$ & $k_{11}^{\prime}$ & $k_{22}^{\prime}$ & $k_{33}^{\prime}$ \\
\hline 1 & 1 & 1 & 1 & 1 & 1 & 1 \\
\hline 2 & 0,2 & 1 & 1 & 1 & 1 & 1 \\
\hline 3 & 1 & 0,2 & 1 & 1 & 1 & 1 \\
\hline 4 & 1 & 1 & 0,2 & 1 & 1 & 1 \\
\hline 5 & 1 & 1 & 1 & 0,2 & 1 & 1 \\
\hline 6 & 1 & 1 & 1 & 1 & 0,2 & 1 \\
\hline 7 & 1 & 1 & 1 & 1 & 1 & 0,2 \\
\hline
\end{tabular}

Table 2: Ratio between permeability values of the different cases solved and experimental permeability values (Table 1 ).

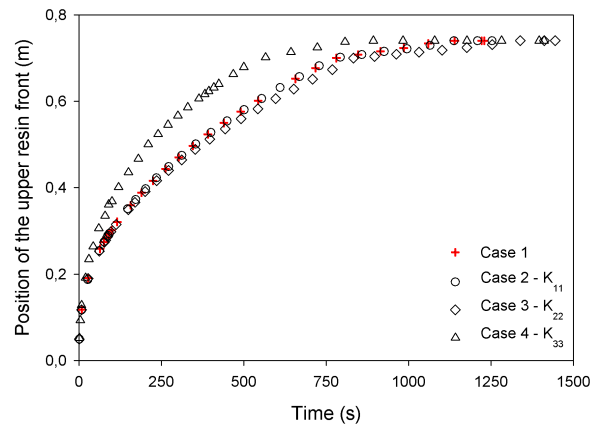

(a)

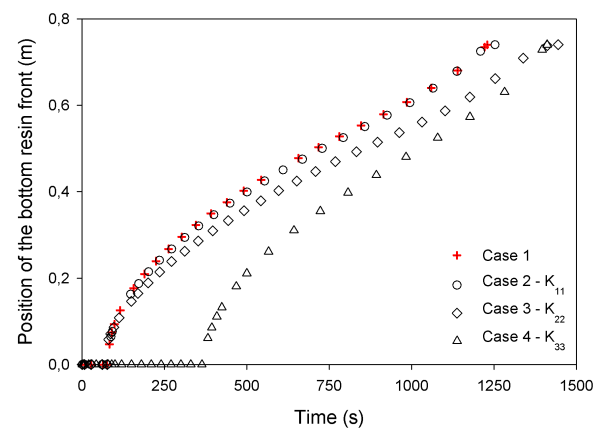

(b)

Figure 10: Cases with variation of the fiberglass permeability values, numerical results. a) Flow front position on the distribution media. b) Flow front position on the bottom ply of the laminate. 


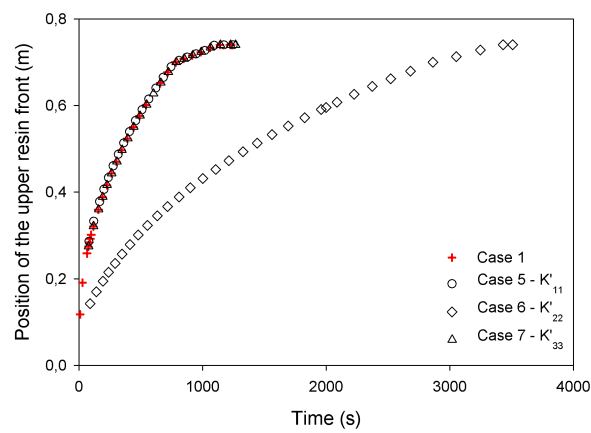

(a)

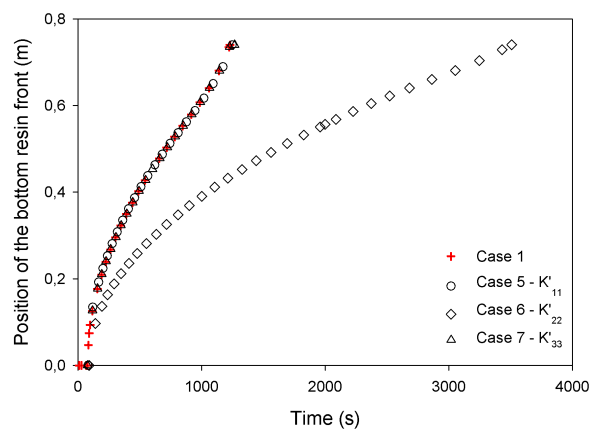

(b)

Figure 11: Cases with variation of the distribution media permeability values, numerical results. a) Flow front position on the distribution media. b) Flow front position on the bottom ply of the laminate.

The results show that the behaviour of the resin infusion is mainly governed by the relation between permeability of the distribution media in the main direction of the resin flow front advance $\left(k_{22}^{\prime}\right)$ and through-thickness permeability of the fibre $\left(k_{33}\right)$ ), as long as the permeability of the distribution media keeps over the in-plane permeability values of the fibreglass fabrics, as expected for resin infusion processes with distribution media. This ratio determines the distribution of the inlet resin flow between the distribution media and laminate, determining the resin flow fronts and filling time. $k_{22}^{\prime}$ determines the distribution of resin in the $x$ axis direction (Fig. 3) and influences decisively on the velocity of flow fronts and on the filling time. The through-thickness resin flow on the laminate and the necessary time to reach the bottom of the laminate by the resin infusion are determined by $k_{33}$ permeability. Fiberglass permeability in the main direction of the resin flow front advance $\left(k_{22}\right)$ influences slightly on velocity of the bottom flow front and mold-filling time. In the studied geometry, the flow front and filling time show a very low sensitivity to changes in the other permeability values.

\subsection{Local effects}

In order to analyze the local effects due to the influence of stacking sequence and properties of the fiber plies of the laminate, the numerical model was solved under different configurations for the laminate. The influence of the plies orientation on the resin flow in areas of the laminate not covered 
by the distribution media (where the flow is not dominated by the permeability of the distribution media in the main direction of the resin flow and by the through-thickness permeability of the preform) can be studied. For instance, the resin flow of a laminate with a symmetric stacking sequence of $[0 / 0 / 0 / 0 / 0 / 0 / 0 / 0 / 0 / 0 / 0 / 0 / 0 / 0 / 0 / 0 / 0 / 0 / 0 / 45]_{S}$ was studied during the filling mold stage. As can be shown in Fig. 12, the resin flow front develops an asymmetric shape after crossing the $45^{\circ}$ oriented layers. In these layers the front moves forward with respect to the layers with a $0^{\circ}$ orientation,, as can be shown in Fig. 12b , which may lead to a defective impregnation of the laminate when the resin flow arrives to the end of the laminate.

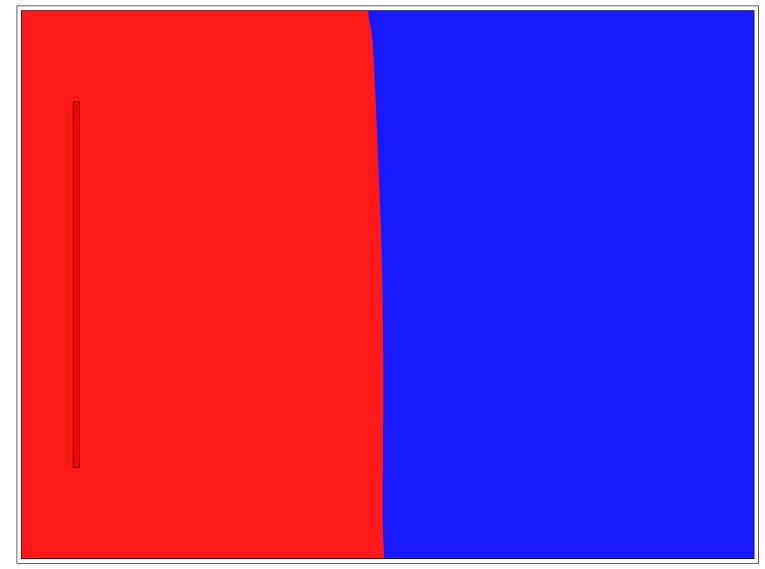

(a)

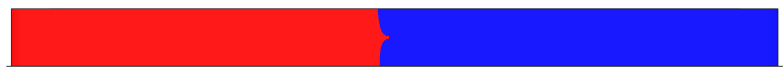

(b)

Figure 12: Resin flow front at a certain of the molding process. a) Central ply of the laminate. b) Central cross section of the laminate.

By the modelling of each ply as a different porous media is possible to simulate the infusion process in laminated composites performed by fabrics with significant different permeability values and fiber volume fractions. The influence of introducing a ply of distribution media in the middle of the laminated composite B is studied. As can be shown in Fig. 13, the resin flow front is very affected by the interior distribution media, developing an 
intermediate front, which accelerates the infusion processby reducing the lead-lag distance (distance between the top and bottom flow front position), but causing air trapping in the end of the laminate.

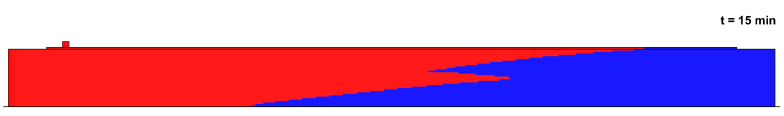

(a)

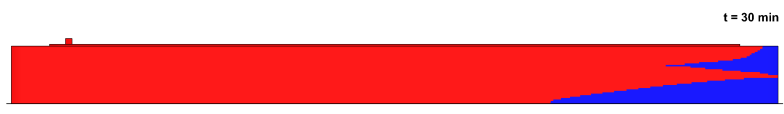

(b)

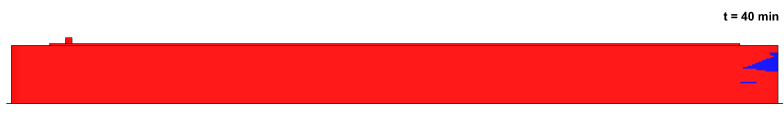

(c)

Figure 13: Resin flow front in the central cross section of the laminate. a) at 15 minutes of the infusion time. b) at 30 minutes of the infusion time. c) at 40 minutes of the infusion time.

A preferential flow on the edge of the laminate can be detected in experimental tests, due to the incorrect adjustment of the vacuum bag on the sides of the laminate close to the vacuum vent, affecting the flow front on the bottom ply (Fig. 14a). This edge effect, also known as race-tracking, is due to the presence of a gap between the laminate and the vacuum bag, providing a channel of low resistance to the flow of resin, and may disrupt the molding process. The edge effect and its influence on the resin flow front in the laminate can be reproduced by the numerical model by adding an empty channel in each side of the laminate (Fig. 14b). Taking into account the technical accuracy of the developed process, the effective cross section of the channels can be calculated, and an inadequate impregnation of the reinforcing material due to the influence of the race tracking can be predicted. 


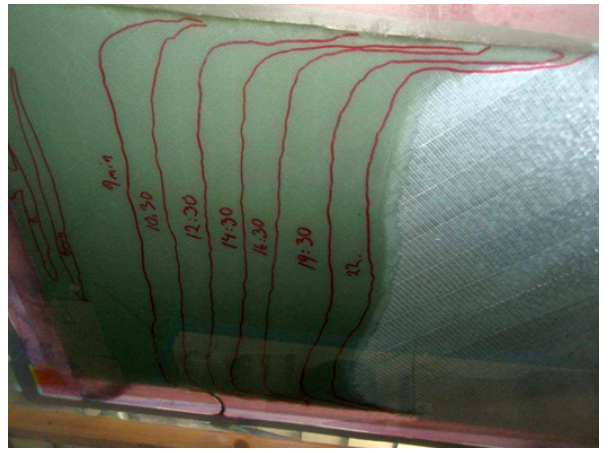

(a)

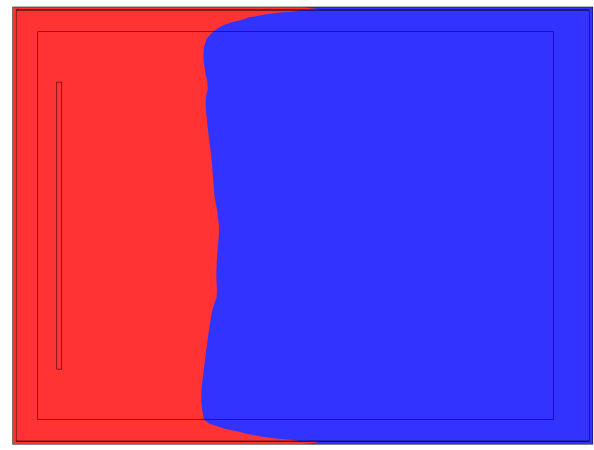

(b)

Figure 14: Race-tracking on the bottom ply of the laminate composite B. a) Experimental test (Courtesy of MTorres). b) Numerical results.

\section{Conclusions}

A 3D multiphasic transient numerical model for the mold filling stage of the vacuum infusion process to manufacture laminated composite materials with different fiber orientations is carried out. The numerical model is validated using data obtained through experimental tests. The numerical results provide the evolution of resin flow through the preform during the molding process, the inlet mass flow, the pressure contours and the velocity vectors in each ply of the laminate, and they predict the possible presence of macroscopic dry areas in the laminate. The pressure contours inside the mold depend on the resin flow front and evolve during the molding stage according to the resin infusion into the laminate. The mass flow of the resin at the inlet section is influenced by the pressure drop inside the mold and it shows four tendencies differentiated by three events during the mold filling process: the filling of the runner, the reaching of the bottom ply of the laminate by resin, and the filling of the distribution media. The mass flow decreases rapidly with increasing the volume of resin inside the mold to a constant value when the mold is completely filled.

The numerical model presented is suitable for the simulation of the mold filling stage for the manufacture of parts by vacuum infusion. The threedimensional model takes into account each ply of the laminate and the orientations of the stacking sequence, and reproduces the asymmetry in the resin 
flow front due to the anisotropy of the reinforcing material fibers and the orientation of each ply with respect to the pressure gradient. The influence of permeability values of fiberglass laminate and of the stacking sequence on the resin distribution during the molding process can be analyzed by the numerical results of the model.

The developed model is quite interesting to study the resin flow in composite parts performed by fabrics with significant different permeability values or by laminates with plies with different ratios between resin and reinforcing material. Moreover, the model allows the detailed study of local effects in which combine flows through porous media and free surface flows, such as the race-tracking on the edge of the laminate.

\section{Acknowledgements}

The research work presented in this paper has been carried out under the project "Automation of the global manufacturing process for wind turbine blades (AQ-BLADE)" IDI-20110154, financially supported by Centro para el Desarrollo Tecnólogico Industrial (CDTI) from the Spanish Government.

\section{References}

[1] Mallik PK. Composites engineering handbook. published by Marcel Dekker, Inc., 1997.

[2] Holmberg JA, Berglund LA. Micromechanisms of delamination failure in RTM U-beams. Compos Part A: Appl Sci Manuf 1997;28A:709-717.

[3] Liu L, Zhang BM, Wang DF, Wu ZJ. Effects of cure cycles on void content and mechanical properties of composite laminates. Compos Struct 2006;73(3):303-9.

[4] Scott AE, Sinclair I, Spearing SM, Mavrogordato MN, Hepples W. Influence of voids on damage mechanisms in carbon/epoxy composites determined via high resolution computed tomography. Compos Sci Technol 2014;90:147-153.

[5] Bertin M, Touchard F, Lafarie-Frenot M-C. Experimental study of the stacking sequence effect on polymer/composite multi-layers submitted to thermomechanical cyclic loadings. Int J Hydrogen Energy 2010;35:11397-11404. 
[6] Scholz S, Gillespie JW, Heider D. Measurement of transverse permeability using gaseous and liquid flow. Compos Part A: Appl Sci Manuf 2007;38:2034-2040.

[7] Park H-J. Effects of stacking sequence and clamping force on the bearing stregths of mechanically fastened joints in composite laminates. Compos Struct 2001;53:213-221

[8] Khashaba UA, Sebaey TA, Alnefaie KA. Failure and reliability analysis of pinned-joints composite laminates: Effects of stacking sequences. Compos Part B 2013;45:1694-1703

[9] Le-Manh T, Lee J. Stacking sequence optimization for maximum strengths of laminated composite plates using genetic algorithm and isogeometric analysis. Compos Struct 2014;116:357-363

[10] Ghiasi H, Pasini D, Lessard L. Optimum stacking sequence design of composite materials Part I: Constant stiffness design. Compos Struct 2009;90:1-11

[11] Liu Q, Parnas RS, Giffard HS. New set-up for in-plane permeability measurement. Compos Part A: Appl Sci Manuf 2007;38(3):954-62.

[12] Endruweit A, Ermanni P. The in-plane permeability of sheared textiles. Experimental observations and a predictive conversion model. Compos Part A: Appl Sci Manuf 2004;35(4):439-51.

[13] Vernet N, et al. Experimental determination of the permeability of engineering textiles: Benchmark II. Compos Part A: Appl Sci Manuf 2014;61:172-184.

[14] Hoes K, Dinescu D, Sol H, Vanheule M, Parnas RS, Luo Y, Verpoest I. New set-up for measurement of permeability properties of fibrous reinforcements for RTM. Compos Part A: Appl Sci Manuf 2002;33:959-969.

[15] Modi D, Correia N, Johnson M, Long A, Rudd C, Robitaille F. Active control of the vacuum infusion process. Compos Part A: Appl Sci Manuf 2007;38:1271-128.

[16] Johnson RJ, Pitchumani R. Simulation of active flow control based on localized preform heating in a VARTM process. Compos Part A: Appl Sci Manuf 2006;37:1815-1830 
[17] Grujicic M, Chittajallu KM, Walsh S. Non-isothermal preform infiltration during the vacuum-assisted resin transfer molding (VARTM) process. Appl Surf Sci 2005;245:51-64

[18] Dong CJ. Development of a process model for the vacuum assisted resin transfer molding simulation by the response surface method. Compos Part A: Appl Sci Manuf 2006;37:1316-1324.

[19] Montés N, Sánchez F. A new computational tool for liquid composite moulding process design based on configuration spaces. Compos Part A: Appl Sci Manuf 2010;41:58-77.

[20] Tan H, Pillai KM. Numerical simulation of reactive flow in liquid composite molding using flux-corrected transport (FCT) based finite element/control volume $(\mathrm{FE} / \mathrm{CV})$ method. Int J Heat Mass Transfer 2010;53:2256-2271.

[21] Trochu F, Ruiz E, Achim V, Soukane S. Advanced numerical simulation of liquid composite molding for process analysis and optimization. Compos Part A: Appl Sci Manuf 2006;37:890-902.

[22] Simacek P, Eksik Ö, Heider D, Gillespie JW, Advani S. Experimental validation of post-filling flow in vacuum assisted resin transfer molding processes. Compos Part A: Appl Sci Manuf 2012;43:370-380.

[23] Liu HL, Hwang WR. Permeability prediction of fibrous porous media with complex 3D architectures. Compos Part A: Appl Sci Manuf 2012;43:2030-2038.

[24] Kuentzer N, Simacek P, Advani SG, Walsh S. Permeability characterization of dual scale fibrous porous media. Compos Part A: Appl Sci Manuf 2006;37:2057-2068.

[25] Tan H, Pillai KM. Multiscale modeling of unsaturated flow in dual-scale fiber preforms of liquid composite molding III: reactive flows. Compos Part A: Appl Sci Manuf 2012;43:29-44.

[26] DeValve C, Pitchumani R. Simulation of void formation in liquid composite molding processes. Compos Part A: Appl Sci Manuf $2013 ; 51: 22-32$. 
[27] Ferland P, Guittard D, Trochu F. Concurrent methods for permeability measurement in resin transfer molding. Polymer composites $1996 ; 17: 149-158$

[28] Berg DC, Dickert M, Meiners D, Ziegmann G. Influence of inaccuracies in permeability measurements. proceedings of ECCM 16, Seville, Spain, 2014.

[29] Sas HS,Wurtzel EB, Simacek P, Advani SG. Effect of relative ply orientation on the through-thickness permeability of unidirectional fabrics. Compos Sci Technol 2014;96:116-121

[30] Darcy H. Les Fontaines Publiques de la Ville de Dijon. Paris: Dalmont, 1856.

[31] FLUENT, 2006. FLUENT 6.3 User's Guide. FLUENT, Inc.

[32] Leonard BP. A stable and accurate convective modelling procedure based on quadratic upstream interpolation. Comp Meth Appl Mech Eng 1979;19:59-98. 